\title{
MUSCLE SPASM IN POLIOMYELITIS
}

\author{
A STUDY OF A NEW ZEALAND EPIDEMIC
}

BY

\author{
J. E. CAUGHEY, M.D.(N.Z.), F.R.C.P., F.R.A.C.P., and \\ D. S. MALCOLM, M.D.(N.Z.), M.R.A.C.P. \\ From the Auckland Hospital
}

(ReCEIVED fOR PUbliCATION August 16, 1949)

The purpose of this article is to record a clinical and experimental study of muscle changes noted in a recent epidemic of poliomyelitis in New Zealand. The term muscle spasm has come into general use to describe those changes which occur in the acute stages of the disease and has to be distinguished from the state of contracture which is a terminal condition of muscle shortening due to fibrosis. In this study we are chiefly concerned with the state of muscle spasm encountered in acute poliomyelitis. The subject of muscle spasm has been a controversial one and skilled observers in the U.S.A. have stated that they encounter muscle spasm in all patients with poliomyelitis, whereas experienced neurologists and orthopaedic surgeons in the United Kingdom and the U.S.A. state that they have never encountered muscle spasm in the disease although, rather curiously, all agree that spasm occurs in the muscles of the neck and back, and in the hamstring muscles.

We regard muscle spasm in poliomyelitis as a state of shortening of muscle, encountered in the acute stage of the disease. Affected muscles are contracted and usually tender on palpation and on stretching; pain usually develops and the spasm increases. In some patients the spasm is not apparent in the muscles until stretch is applied.

\section{Clinical Observations}

Incidence of muscle spasm. At the outset of the epidemic attention was focused on the extensor muscles of the neck and spine and on the hamstring muscles, those muscles which in the past have been held to be affected by so-called 'meningeal irritation.' In our first 124 patients, evidence of muscle spasm in these muscle groups was detected in 89 per cent. Thereafter, it was realized that our method of examination for muscle spasm was inadequate and that a complete examination of a poliomyelitis patient, in addition to the usual examination of all systems, entailed a search for muscle spasm by a detailed inspection of all muscle groups, and further, big muscle groups should be taken through their full range of movement in order to observe the effect of stretch on the muscles. An examination of forty consecutive patients carried out in this manner revealed evidence of muscle spasm in 100 per cent.

TABLE I

INCIDENCE OF MUSCLE SPASM

\begin{tabular}{|c|c|c|c|c|}
\hline & \multicolumn{2}{|c|}{ First 124 Cases } & \multicolumn{2}{|c|}{ Last 40 Cases } \\
\hline & No. & $\begin{array}{c}\text { Percent- } \\
\text { age }\end{array}$ & No. & $\begin{array}{l}\text { Percent- } \\
\text { age }\end{array}$ \\
\hline $\begin{array}{l}\text { Neck rigidity } \\
\text { Back rigidity } \\
\text { Kernig sign } \\
\text { Spasm of } \\
\text { other muscle } \\
\text { groups } \\
\text { Cases having } \\
\text { one or other } \\
\text { of above .. }\end{array}$ & $\begin{array}{c}90 \\
101 \\
96 \\
\\
\text { Not fully } \\
\text { examined }\end{array}$ & $\begin{array}{c}73 \\
81 \\
77 \\
\\
\text { Not fully } \\
\text { examined }\end{array}$ & $\begin{array}{l}25 \\
25 \\
18\end{array}$ & $\begin{array}{l}63 \\
63 \\
45\end{array}$ \\
\hline
\end{tabular}

Method of examination. This is best carried out in a warm room, with the patient clad in a pair of shorts and lying on a plinth, rather than on a bed. The patient is first inspected in the supine position for deviation of the head to the right or left or for undue extension of the head. The shoulders are examined for so-called ' cupping' in which there is updrawing and rotation forward of the shoulders, and the biceps for spasm which causes flexion at the elbows. Next the patient is inspected in the lumbar region for exaggeration of the normal lumbar lordosis or for scoliosis. On assuming the sitting posture, spasm and pain cause the patient to assume the 'tripod' posture with the knees and hips flexed, the lumbar region held straight and rigid and the body weight supported by the arms which are extennded backwards (fig. 1). Before sitting up the legs should be carefully straightened out on the bed so that the internal malleoli are together. This may be difficult on account of spasm in the hamstring muscles. On sitting the patient up, one leg may shoot forward further than the other due to slight protective flexion at the hip on the affected side. The feet are inspected for inversion or eversion and for plantar flexion due 
to spasm of the gastrocnemius muscle. The patient is then turned to the prone position in order to inspect the back muscles and the glutei muscles. After inspection in the above manner major muscles groups are stretched by taking them through their full range of movement. The trapezius muscle is tested by separating the head from each shoulder in turn. The usual test for neck rigidity is carried

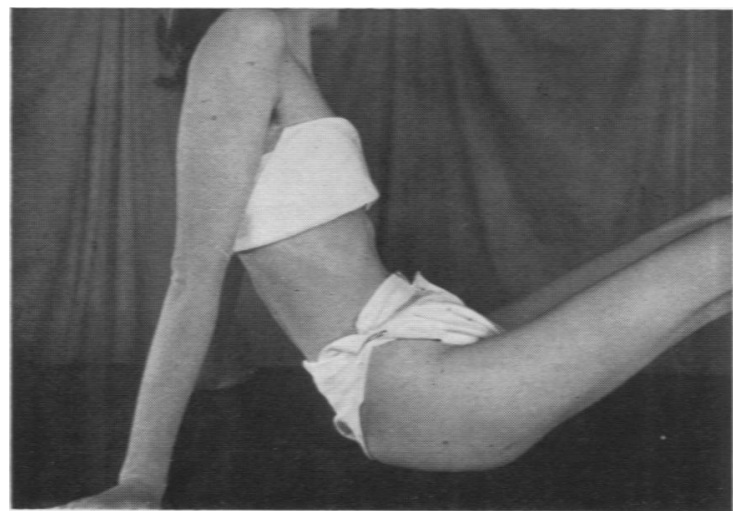

FIG. 1.-Tripod position with muscle spasm of the lumbar and hamstring muscles.

out by slowly flexing the head. The muscles around the shoulder girdle are stretched by full abduction of the arm, and the biceps and triceps by full flexion and extension at the elbows. The lumbar muscles are stretched by lateral flexion to right and left and by asking the patient to touch the toes with the legs extended on the bed. Slight scoliosis of the spine may only be apparent when the patient stands and attempts to touch the toes, bending down and coming up slowly. The quadriceps may be stretched by full flexion by attempting to place the heel on the buttock or by turning the patient into the prone position and again attempting to put the heel on the buttock. The hamstring muscles are stretched by the usual Kernig test and the gastrocnemii muscles by dorsiflexion of the feet.

Manifestations of muscle spasm. Muscle spasm may be apparent when the patient is in a resting position. The affected muscles are usually tender on deep palpation and may be exquisitely so. To the touch they appear to be firmly contracted and the muscle tendons are tight. Stretching has the effect of increasing the muscle spasm in muscles already obviously in spasm and it may induce spasm in muscles which are apparently free of spasm. It is probable that the muscle spasm which is apparent at rest is brought about by stretch which is the result of postural change.

The effect of stretch is variable. In some patients muscles pass into painful spasm on the slightest stretch, and in others muscles can be taken almost to the end point of stretch before the patient complains of tightness and discomfort and spasm develops. The increase of spasm or the development of spasm on stretch usually occurs at the onset of a phase of painful stretch, but not invariably. It might be suggested that pain had set up an abnormally active stretch reflex. On the release of stretch to a point just short of pain the spasm passes off. If muscles are stretched beyond the onset of spasm resistance to further stretch increases. The degree of possible further stretch varies, and is limited at some times by extreme spasm and at other times by spasm and severe pain.

The sites of muscle spasm. The extensor muscles of the head and spine were those most commonly affected. In most patients the spasm of these muscles was apparent on stretch alone. In severe cases extension of the neck and back was apparent at rest and the knees were partially flexed. On occasions one side was more affected than the other, causing deviation of the head to one side, a tight ligamentum nuchae on one side or a scoliosis. When one lumbar group was more affected than the other there was flattening of the muscles on the affected side with a scoliosis with the concavity to the side of the flattened tight muscles. Muscles around the shoulder girdle were commonly affected causing the characteristic deformity referred to above. Spasm of the pectoral and latissimus dorsi muscles prevented complete abduction at the shoulder. The flexors of the forearm were sometimes affected and at times the pelvic girdle was tilted by spasm. In the thighs, the quadriceps muscles at times were partially or completely involved preventing complete flexion at the knee; when tested by flexion of the knee with the patient lying in the prone position, spasm and pain in the quadriceps muscle led to protective elevation of the buttock caused by flexion at the hip (fig. 2).

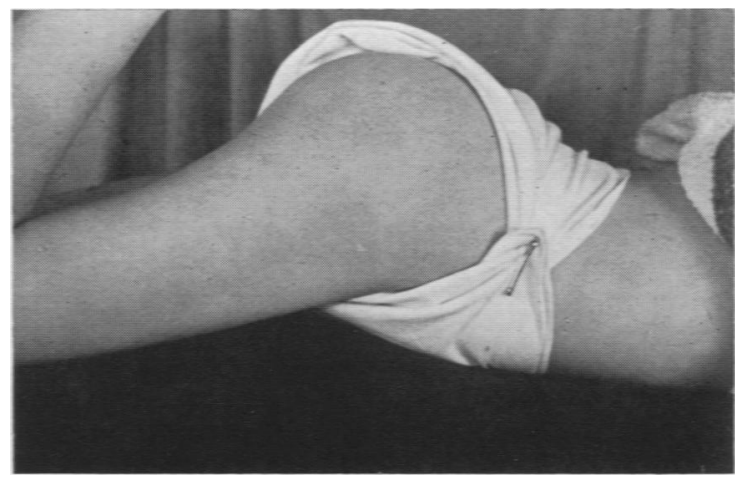

FIG. 2.-Spasm of quadriceps muscle with protective flexion at the hip on attempting to place the heel on the buttock.

Tightness of the gastrocnemius muscle was apparent on dorsiflexion of the foot, and, in some, spasm caused inversion or eversion of the foot. Spasm of the plantar muscles produced tightness and narrowing of the plantar fascia. 
Other clinical features of muscle spasm. Aggravation of muscle spasm was caused by various activities, such as heavy massage or rough handling of muscles. Premature weight bearing with too early ambulation without adequate support (such as elbow crutches) also caused aggravation. On occasion patients were discharged from hospital apparently well, but after a time at home, as a result of unsuitablè regulation of motor activity, muscle spasm developed again, at times necessitating further periods in hospital. For this reason, patients, when discharged, were advised to refrain from athletics, cycling; digging or other very strenuous activities for a few months, and for a time were examined regularly as out-patients. Exposure to cold caused aggravation in convalescent patients and sometimes was responsible for unmasking muscle spasm in mild cases which otherwise would not have been diagnosed as poliomyelitis. The effect of fever was apparent when an epidemic of influenza occurred. One girl, aged seventeen years, who had marked muscle spasm on admission, was almost symptom-free after six weeks. She then developed an attack of influenza (Type B. strain Lee), and with the onset of this intercurrent infection there was a prompt return of muscle spasm in the muscles previously affected. No change in the spinal fluid developed during this relapse. A similar reactivation of spasm was seen in some children who developed chickenpox and in some with mild upper respiratory infection.

No correlation was found between the degree of muscle spasm and the cell count of the spinal fluid. We encountered marked spasm in the presence of a normal spinal fluid and it was found to persist for weeks after the spinal fluid had returned to normal. During the epidemic many cases presented with a typical history of onset and characteristic muscle spasm without paresis or changes in the spinal fluid. Some muscles, apparently devoid of power, were found to be in a state of muscle spasm. This usually occurred as a result of reflex inhibition, due to fear of pain, and, on relief of the spasm and pain, power returned. At times weakness was the result of a disturbance of reciprocal innervation. The effect of effort in relation to the degree of paralysis has been noted by other observers. We have occasionally observed extreme aggravation of muscle spasm following strenuous exercise soon after the onset of the disease. One adult woman, two days after the onset of fever, danced for four hours and the following morning presented a picture of extreme spasm in many muscle groups, especially in the back and lower extremities.

\section{The Relationship of Muscle Spasm to Paresis}

The incidence of muscle spasm in the New Zealand epidemic was very high and occurred in 100 per cent. of cases fully examined. The incidence of paresis in the first 224 patients was $49 \cdot 1$ per cent. (110 patients).
Effect of treatment. Treatment of all patients in the acute stages of the disease was directed to the relief of muscle spasm and pain. Patients were nursed on a firm mattress which gave adequate splintage to the back muscles, and the feet rested against a foot board. The legs were prevented from rotating by sandbags and the weight of the bedclothes was taken by a cradle.

The relief of muscle spasm was accomplished by the use of hot packs made of a fine woollen material dipped in boiling water, wrung dry in an extractor, and applied at a high temperature. These packs were applied at hourly to four-hourly intervals during the day, and at night if required. This method of treatment relieved muscle spasm and produced a marked degree of comfort.

The ultimate state of muscles in spasm could not be predicted with certainty. The usual outcome was resolution of the muscle spasm without residual weakness or contracture. This resolution sometimes occurred within a few days; at other times it was delayed for many weeks. In some, the spasm passed into a state of permanent contracture due to fibrosis, which was an important factor in the production of deformities such as scoliosis. Some muscles in spasm passed into a state of partial or complete flaccid paralysis.

\section{Electromyographic Studies}

In an attempt to determine the site and nature of muscle spasm we made electromyographic studies on five normal patients and on twenty patients with poliomyelitis in various stages.

Method. The muscle action potentials were amplified by an all-mains operated amplifier. This was a resistance-capacity coupled amplifier, single ended, with a maximum gain which enables a $2 \mathrm{~cm}$. oscillograph spot deflection to be obtained with an input signal of 100 microvolts. The amplified potential changes were led to two Cossor cathode ray oscillographs as well as to a loud speaker (Weddell et al., 1944). It was therefore possible to view the action potentials on one oscillograph screen while these were being photographed on the other screen. As no screened room was available the amplifier was so constructed that the frequency response was substantially flat between 20 cycles and 2,000 cycles per second. All the records were obtained by the use of a concentric needle electrode in which the electrodes were threaded through a hypodermic needle so that the tips lay in the bevel of the needle (Adrion and Bronk, 1929). The action potential of a motor unit can give rise to a recordable impulse for a distance of the order of $1 \mathrm{~cm}$. from the copper tip of the needle (Weddell et al., 1944) and, in order to sample as large an extent of the muscle as possible, the needle was moved in several directions once the tip had penetrated the deep fascia and observations were made of the electrical potentials in each position. Thus the effects of physiological rest, of contraction, and of passive stretch were investigated. 
Observations. The following observations were made (1) on normal muscles; (2) on muscles in spasm (a) at rest; (b) on passive stretch; and (c) on voluntary contraction.

Normals. In five normal subjects, on complete relaxation of the quadriceps muscle and on passive stretching of the muscle, no electrical potential changes were heard or seen but, on voluntary contraction, normal motor unit activity was demonstrated. The complexity of the tracing in respect of amplitude and frequency was dependent upon the force of the contraction.

discharges from such muscles (figs. 3, 4, 5) as reported by Watkins et al. (1943).

(b) ON PASSIVE STRETCH. Each muscle was then submitted to a slow stretch to a point of discomfort or pain at which the muscle spasm developed, and in most cases action potentials developed. This, however, was not invariable. In a few cases, no potentials developed on stretch either with or without pain in spite of the development of spasm. In most cases, stretch was limited by maximum spasm and pain, in some by spasm alone, and at this point action potentials recorded were at a maximum.

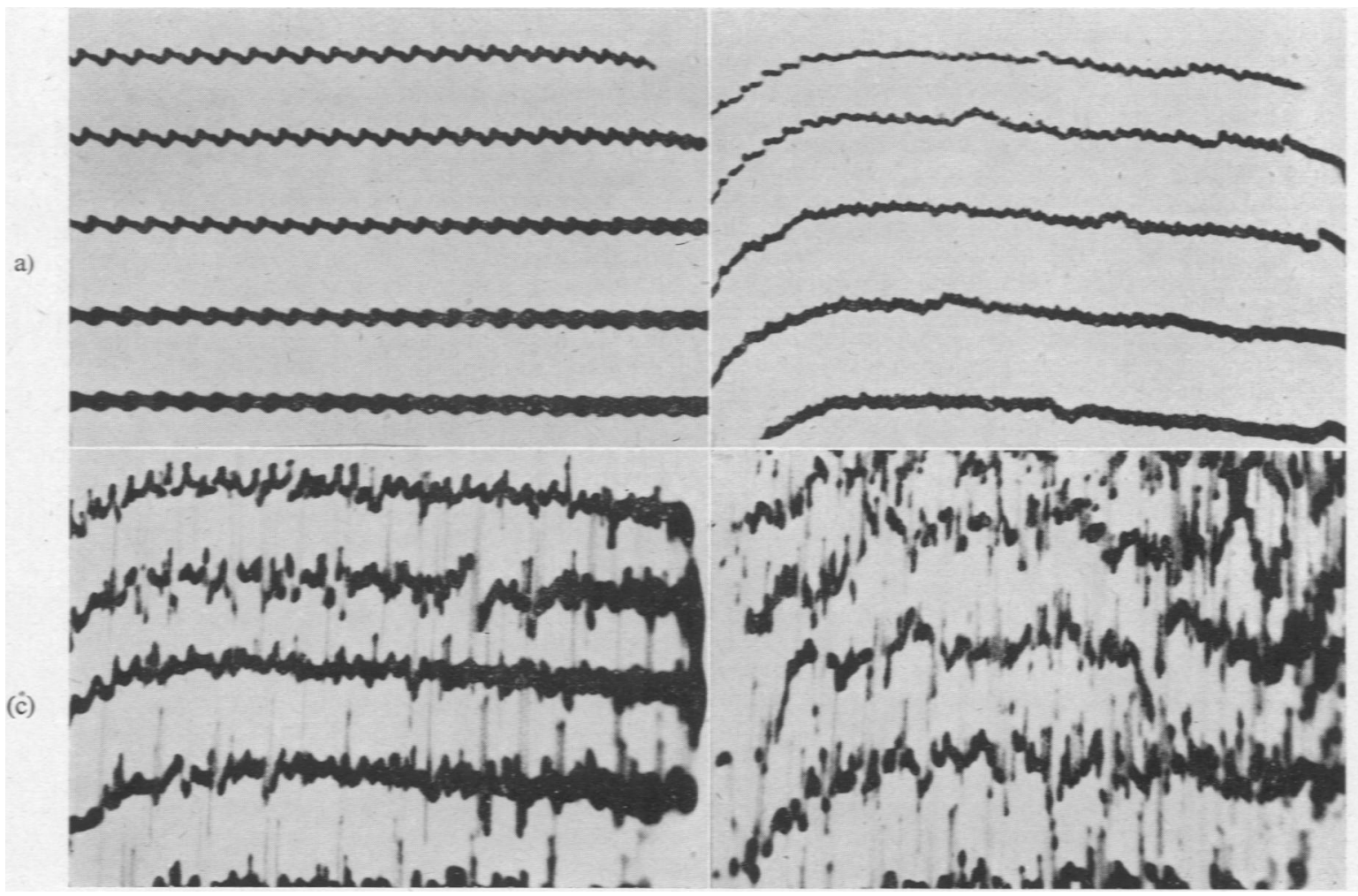

FIG. 3.-Electromyographs from patient with acute poliomyelitis with spasm of the right quadriceps muscle. (a) Muscle at rest; (b) effect of stretch which did not cause pain: (c) effect of painful stretch; (d) effect of voluntary contraction.

Muscles In SPASM (a) AT REST. When the insertion action potentials had settled down, in most instances but not invariably, in a muscle which was clinically in a state of muscle spasm, there was electrical silence while the muscle was at rest. In some such muscles multiple sampling was carried out in order to confirm the result. In some muscles, fibrillation potentials were demonstrated, but in others which had had demonstrable spasm for more than three weeks, no fibrillation potentials were detected. We did not encounter spontaneous
These action potentials first appeared as the muscles entered the stage of painful stretch. In general, if some motor power was preserved, the action potentials on voluntary contraction were greater than those elicited on stretch. In some muscles, apparently paretic and in spasm, no action potentials could be elicited either on attempted voluntary contraction or on stretch, even to a point of severe pain. On slight relaxation, just to the point where pain ceased, the action potentials disappeared. We have not examined any muscle in which the unit 
activity on stretch was greater than on full voluntary contraction as suggested by Watkins et al. (1943).

(c) ON VOLUNTARY CONTRACTION. In muscles in spasm capable of voluntary contraction, the frequency and amplitude of the action potentials obtained was in direct proportion to the degree of voluntary power present in the muscle.

\section{Spinal Anaesthetic Studies}

Kabat and Knapp

(1944) tested five patients with spinal anaesthesia, three in the acute and subacute stage of the disease, and two in the chronic stage. Those in the acute and subacute stage showed relaxation of the muscle spasm under a spinal anaesthetic (heavy percaine). In two patients, fourteen months after the onset of the disease, spinal anaesthesia produced practically no change in the limitation of passive movement. Cook (quoted by Kabat and Knapp) in two patients in the first two weeks of the disease, found that spinal anaesthesia eliminated muscle spasm. In two patients under spinal anaesthesia, Kabat and Knapp found that when sensory anaesthesia was produced and some motor function still persisted, the restriction of passive movement was reduced but it was not completely eliminated until muscular paresis had developed.

We have studied the effect of spinal anaesthesia on four patients, two in the acute stage of the disease twenty and twenty-five days after the onset, and two in the chronic stage eighty-five and sixtythree days after the onset. Our yardstick was the goniometer, with which was measured the angle of flexion at the knee joint in checking the hamstring muscles and quadriceps muscles and the angle of flexion of the spine before and after spinal anaesthesia, using $2 \mathrm{ml}$. of heavy percaine. In the patients in the acute phase of the disease, spasm of the hamstrings, quadriceps, and back-muscles was relieved. I In the two patients in the chronic stage of the illness no relief was obtained. Hence, our observations conform to those of Kabat and Knapp and other observers (table 2).

\section{Curare Studies}

In this our experience was very limited but will be quoted. In two patients in the acute phase of the illness (sixteen and twenty days from the time of onset) curare ( $2 \mathrm{ml}$. 'intocostrin') failed to relieve muscle spasm. The curarized muscles were still painful on stretch. This small experience coincides with that of others (Kottke et al., 1948; Elkins and Carbin, 1947) in respect of curare.

Discussion
Various authors
have focused atten-
tion on the wide-
spread nature of the
lesions throughout
the central nervous
system. The main
brunt of the lesion
falls on the anterior
horn cells of the
spinal cord, on the
internuncial cells of
the cord and on the
reticulum formation
and tegmentum of the
brain stem (Barnhart
et al.). The changes

FIG. 5. Electromyographs of a muscle clinically showing spasm (1) at rest; (2) during maximum voluntary contraction; (3) during painful stretch of the muscle, demonstrating absence of activity.

et al.). The changes in the meninges have received little attention. Scheinker (1947) has demonstrated changes in the leptomeninges similar to those in the cord. The meningeal infiltration varied considerably at different levels of the spinal cord and the cerebral meninges were affected only in the region of the mid-brain 
and cerebellum. Freeman (1933) found infiltration of the meninges by lymphocytes at the base of the brain and particularly along the cord meninges. More recently changes in the muscles have been noted. Hassin (1943) has reported parenchymatous swelling and disruption of muscle fibres and also diffuse and.focal inflammatory infiltration in a patient who died two hours after the onset of paralysis. Carey (1944) has studied muscles and their neuromuscular junctions, and has demonstrated in post-mortem material from three patients denervation of the extrafusal fibres within thirty-six hours of the onset of paralysis.

Older views on the normal mode of action of the spinal cord have to be revised in the light of recent work. We now have to visualize two opposing sets of impulses, excitatory and inhibitory, playing on the final common pathway, the anterior horn cell. In man, cortical suppressor bands have been proven in area $4 \mathrm{~s}$. This suppressor system passes via the internal capsule to the caudate nucleus which relays to the red nucleus, substantia nigra, globus pallidus, subthalamic body, and the thalamus. From these nuclei, relays pass down the brain stem to the reticular nuclei, whence the band of suppressor bulbospinal fibres arise, pass to the internuncial pool, and thence to the final common pathway, the anterior horn cell. On available evidence it seems that the reticulospinal system constitutes an efferent pathway from the higher centres to the local spinal reflex system whose activity is expressed as suppression of anterior motor neurone discharge.

Various investigators have attempted to correlate exactly the known pathology with the state of spasm found on clinical examination, and have arrived at widely divergent opinions as to the site of the lesion responsible for the spasm, ranging from the reticulum in the bulbar region, the meninges, the internuncial cells, the anterior horn cells, to the muscle fibres themselves. Moldaver (1944) suggested that muscle spasm was made up of three components; meningeal irritation in the acute phase; increased stretch reflex due to paralysis of antagonists and hyper-irritability of inflamed posterior root ganglia. Kabat and Knapp (1944) have postulated damage of the internuncial neurones as the cause of spasm which results from release of proprioceptive reflexes from inhibition. Bodian (1946) has correlated injury to the bulbar inhibiting mechanism with the appearance of generalized spasticity in experimental poliomyelitis in monkeys, and Pohl (1943 and 1945) states that the present Kenny concept of the disease is that it is primarily an affection of peripheral structures, principally the muscles and their fascial coverings, but also including the skin and subcutaneous tissues.

Lesions of the suppressor system at different levels have been held to be responsible for muscle spasm as a result of the removal of inhibiting impulses and the resultant activation of the excitatory motor system. Relief of spasm by a spinal anaesthetic would support this view. On the other hand, a lesion of the suppressor system at the cortex, bulbar region or internuncial pool, would be expected to give rise to an upper motor neurone type of lesion with hyper-reflexia and a 'clasp knife' type of rigidity. We find, however, a different state from the hypertonus of the upper motor neurone lesion.

A consideration of our own findings suggests that more than one lesion accounts for the phenomena of muscle spasm.

Meningeal irritation. The available evidence lends some support to the theory of so-called 'meningeal irritation,' that is, reflex muscle spasm induced by irritation of pain-sensitive structures in the meninges or dorsal nerve roots such as occurs in meningitis or subarachnoid haemorrhage. By a series of studies Wolff (1947) demonstrates that noxious stimulation in any part of the cranium may lead to sustained contraction of the head and neck muscles. Pathological changes of the spinal fluid and meninges in poliomyelitis are well established and we believe that this inflammation causes irritation to the pain-sensitive structures and, as a result, reflex spasm of muscles of the neck, back,

TABLE 2

ANALYSIS OF DEGREES OF RELAXATION OBTAINED UNDER SPINAL ANAESTHESIA

\begin{tabular}{|c|c|c|c|c|c|}
\hline \multirow[t]{2}{*}{ Patient } & \multirow[t]{2}{*}{ No. of Days of Illness } & \multicolumn{3}{|c|}{$\begin{array}{c}\text { Effect of Spinal Anaesthesia (Heavy } \\
\text { Percaine) }\end{array}$} & \multirow[t]{2}{*}{ Comment } \\
\hline & & Before & & After & \\
\hline $\begin{array}{l}1 \\
2 \\
3\end{array}$ & $\begin{array}{l}85 \\
63 \\
20\end{array}$ & $\begin{array}{l}\text { *Kernig (R) } \\
\text { +Quadriceps (R) } \\
\text { Quadriceps (R) }\end{array}$ & $\begin{array}{r}145^{\circ} \\
30^{\circ} \\
20^{\circ} \\
30^{\circ}\end{array}$ & $\begin{array}{r}145= \\
30= \\
0= \\
10=\end{array}$ & $\begin{array}{l}\text { No alteration } \\
\text { No alteration } \\
\text { Definite relaxation }\end{array}$ \\
\hline 4 & 25 & $\begin{array}{l}+ \text { Back } \\
\text { Kernig (R) } \\
\text { (L) }\end{array}$ & $\begin{array}{r}65^{\circ} \\
120^{\circ} \\
110^{\circ}\end{array}$ & $\begin{array}{r}85^{\circ} \\
150^{\circ} \\
155^{\circ}\end{array}$ & Definite relaxation \\
\hline
\end{tabular}

- Kernig angles were measured as angle between leg and vertical thigh.

+ Quadriceps angles were measured as angle between leg and thigh when heel was approximated to the buttock.

¥ Back angle was measured between horizontal plane of the bed and lumbar region when patient was leaning forward as far as possible. 
and lower limbs. The release of spasm of the lower limbs by spinal anaesthesia in the acute phase of the disease would support this contention. There is, however, no apparent correlation between the number of cells in the spinal fluid and the degree of muscle spasm, as many cases have been shown to present with muscle spasm alone and a normal spinal fluid and, in the case quoted above, when muscle spasm was reactivated by fever, there was no evidence from the spinal fluid examination, as judged by the cell count, of a further meningeal lesion.

Peripheral lesion. The available evidence also lends some support to the suggestion of a peripheral lesion in the muscle itself, at the myoneural junction, or in the muscle protoplasm. Some pathological evidence has been quoted, and requires careful checking. Clinically the muscles are found to be tender on palpation and on stretch. The relief of the spasm by the application of hot packs might suggest a local lesion. It has been noted that at times the spasm is aggravated by motor activity, a febrile illness, or exposure to cold. These three factors normally induce muscle stiffness and all have the effect of increasing the metabolic rate with an increase of metabolites which may impair the chemical action at a damaged myoneural junction.

Electromyographic studies with our instrument failed to reveal motor potentials in spasm in spite of multiple sampling in some cases, and this suggests a primary involvement of the contractile mechanism of the muscle. The hyperirritability of the muscle on stretch suggests a sensitivity of the muscle spindles themselves. The relief of spasm in the acute phase by a spinal anaesthetic could be brought about by the abolition of pain or by the dilatation of blood vessels as probably occurs with the application of hot packs. The failure of curare to give relief favours the diagnosis of a lesion of the contractile tissue. Spasm may occur in muscles devoid of voluntary power and these muscles may go on to a flaccid paralysis suggesting that muscle spasm is not dependent upon the existence of an intact reflex arc. All these factors suggest that spasm in the acute phase is not entirely a function of the ordinary motor neurone.

\section{Summary}

We have found muscle spasm in all patients with poliomyelitis. It may be present at rest and is increased by stretch. It may resolve, or a muscle so affected may pass into a state of flaccid paralysis, or into a state of contracture.
Our electromyographic studies have failed to demonstrate electrical potentials in muscles in a state of spasm. We find increased sensitivity or hyperirritability of the stretch reflex.

Spinal anaesthesia relieved spasm in the acute stage of the illness but not in the chronic stage. Curare failed to relieve spasm in the acute stage of the illness.

In the acute phase of poliomyelitis, we believe the muscle spasm is in part the result of reflex spasm due to meningeal inflammatory changes irritating the pain-sensitive structures of the meninges and dorsal roots, and in part to a local lesion in the muscles themselves.

We have to thank Dr. Elizabeth Hughes who has given us access to her cases and has co-operated with us in this study; the N.Z. Medical Research Council for the release of the apparatus; Professor J. C. Eccles for his advice and assistance in this investigation. Mr. E. E. Suckling has given us technical advice, and Mr. Litherland has prepared the photographs.

\section{REFERENCES}

Adrian, E. D., and Bronk, D. W. (1929). J. Physiol., $67,119$.

Barnhart, M., Rhines, R., McCarter, J. C., and Magoun, H. W. (1948). Arch. Neurol. Psychiat., Chicago, 59,368 .

Bodian, D. (1946). Proc. Soc. exp. Biol., N.Y., 61, 170.

Carey, E. J., et. al. (1944). J. Neuropath. exp. Neurol., 3,121 .

Freeman, W. (1933). 'Neuropathology.' Saunders. Philadelphia.

Hassin, G. B. (1943). J. Neuropath. exp. Neurol., 2, 293.

Kagbat, H., and Knapp, M. E. (1943). J. Amer. med. Ass., $122,989$.

- - (1944). J. Pediat., 24, 123.

Kottke, F. J., Teigen, B. S., Seigel, S., and Knapp, M. E. (1948). Arch. phys. Med., 29, 141.

Moldaver, J. (1944). J. Bone Jt. Surg., 26, 103.

Pohl, J. F. (1945). Lancet, 65, 265.

- - and Kenny, E. (1943). 'The Kenny Concept of Infantile Paralysis and its Treatment.' Minneapolis. Bruce Pub. Co.

Richards, R. L., Elkins, E. C., and Corbin, K. B. (1947). Proc. Mayo Clin., 22, 34.

Scheinker, I. M. (1947). Arch. Neurol. Psychiat., Chicago, 57, 565.

Watkins, A. L., Brazier, M. A. B., and Schwab, R. S. (1943). J. Amer. med. Ass., 123, 188.

Weddell, G., Feinstein, B., and Pattle, R. E. (1944). Brain, 67, 178.

Wolff, H. G. (1947). In MacBryde, C. M., ' Signs and Symptoms.' Lippincott. Philadelphia. 